\title{
AVALIAÇÃO FISIOLÓGICA DE SEMENTES DE ARROZ SUBMETIDAS A DOSES DE BIOESTIMULANTE
}

\author{
RODRIGUES, Lennis Afraire ${ }^{1}$ \\ BATISTA, Mariana Silveira ${ }^{2}$ \\ ALVAREZ, Rita Cássia Félix ${ }^{3}$ \\ LIMA, Sebastião Ferreira ${ }^{4}$ \\ ALVES, Charline Zaratin
}

RESUMO: Os bioestimulantes são compostos por fitormônios e têm efeito sobre o metabolismo de diferentes plantas, sendo aplicados, usualmente, sobre as sementes em culturas no momento da semeadura. Dessa forma, é fundamental conhecer os efeitos desse produto na qualidade fisiológica de sementes. Assim, este trabalho objetivou avaliar o efeito de doses de bioestimulante nas características fisiológicas de sementes de arroz. Os tratamentos constituíram-se de doses crescentes do produto comercial Stimulate ${ }^{\circ}(0,250,500,750$ e $1000 \mathrm{ml}$ para $100 \mathrm{~kg}$ de sementes) adicionadas diretamente às sementes de arroz, cultivar Primavera. Os testes para avaliação da germinação e vigor foram: primeira contagem de germinação, germinação, emergência, índice de velocidade de emergência, comprimento do sistema radicular e parte aérea, massa de matéria seca da raiz e parte aérea. O comprimento da parte aérea aumentou com as doses crescentes de Stimulate ${ }^{\circledR}$. A germinação, o comprimento de raiz, a massa de matéria seca da raiz e parte aérea, o índice de velocidade de emergência e a percentagem de emergência não foram afetados pelas doses de Stimulate. Doses de $1000 \mathrm{~mL}$ para $100 \mathrm{~kg}$ sementes, podem ser utilizadas no arroz, aumentando o comprimento da parte aérea, mas sem afetar a germinação das sementes.

Palavras chaves: Oryza sativa. Stimulate. Fitormônios. Germinação.

\section{PHYSIOLOGICAL EVALUATION OF SEEDS OF RICE UNDER DOSE OF BIOSTIMULANT}

SUMMARY: The biostimulants are composed of phytohormones and have effect on the metabolism of various plants and are applied usually on the seed at sowing crops moment. Therefore, it is important to know the effects of this product on the physiological quality of seeds. Thus, this study aimed to evaluate the effect of doses of biostimulants on physiological characteristics of rice seeds. The treatments consisted of increasing doses of the commercial product Stimulate $^{\circledR}(0,250,500,750$ and $1000 \mathrm{ml}$ for $100 \mathrm{~kg}$ of seeds) added directly on the rice seed cultivate Primavera. For germination and vigor, treated seeds were subjected to the following tests: first count (PCG), germination (G), emergence (E), speed of emergence (IVE), length of the root system (CSR) and shoot (CPA), dry matter of the root (MSR) and shoot (MPA). The shoot length increased with increasing doses of Stimulate ${ }^{\circledR}$. The germination, root length, the dry mass of roots and shoots, the rate of emergence rate and percentage of emergence were not affected by the doses of Stimulate. Doses of $1000 \mathrm{~mL}$ per $100 \mathrm{~kg}$ seed can be used in rice, increasing the shoot length, but without affecting the germination of seeds.

Keywords: Oryza sativa. Stimulate. Phytohormones. Germination

\footnotetext{
${ }^{1}$ Universidade Federal de Mato Grosso do Sul/Campus de Chapadão do Sul - Mestranda em Produção vegetal, UFMS

${ }^{2}$ UNESP, Ilha Solteira - Mestranda em Produção Vegetal, Unesp - FEIS

${ }^{3}$ Universidade Federal de Mato Grosso do Sul/Campus de Chapadão do Sul - Doutora em Fitotecnia pela Unesp de Botucatu. Professora Adjunta da UFMS no curso de Agronomia

${ }^{4}$ Universidade Federal de Mato Grosso do Sul/Campus de Chapadão do Sul - Doutor em Fitotecnia pela Universidade Federal de Viçosa. Professor Adjunto da UFMS nos cursos de Agronomia e Engenharia Florestal

${ }^{5}$ Universidade Federal de Mato Grosso do Sul/Campus de Chapadão do Sul - Professor Doutora da UFMS. Área de sementes
} 


\section{INTRODUCÃO}

Os cereais mais produzidos e consumidos no mundo são o arroz (Oriza sativa), o trigo (Triticum aestivum L.) e o milho (Zea mays L.) (USDA, 2009). No Brasil, o arroz representa a terceira cultura anual que mais produz e são cultivados anualmente cerca de 2,4 milhões de hectares, com produção de 12,2 milhões de toneladas (CONAB, 2014).

Mais de $75 \%$ da produção de arroz é oriunda do sistema de cultivo irrigado por inundação (EMBRAPA, 2005), o qual possui alta necessidade de água quando comparado com outros sistemas de irrigação. Além disso, este sistema apresenta altos custos de produção, o que aumenta a necessidade de pesquisas em busca de novas alternativas para elevar o retorno econômico aos agricultores (GIACOMELI et al., 2013). Tendo em vista esta necessidade, atualmente existem produtos bioestimulantes que proporcionam melhorias no desempenho das sementes, suas respectivas plântulas e até mesmo em estádio mais avançados da cultura. As plantas mais vigorosas refletem em estande mais uniforme potencializando a capacidade produtiva da cultura.

Os bioestimulantes são definidos como a mistura de dois ou mais reguladores vegetais com outros compostos de natureza química diferentes, como minerais ou aminoácidos (CASTRO et al., 2008), que podem ser aplicados diretamente nas plantas ou em tratamento de sementes (KLAHOLD et al., 2006), objetivando maiores produções e melhorias na qualidade das sementes. O biorregulador favorece a expressão do potencial genético da planta por promover equilibro hormonal e estimular o crescimento radicular (SILVA et al., 2008). Esses produtos podem aumentar a absorção de água e nutrientes pelas plantas e propiciar maior resistência ao estresse hídrico e aos efeitos residuais de herbicidas, tornando-os de grande interesse para o uso na agricultura (VASCONCELOS, 2006).

O Stimulate ${ }^{\circledR}$, produto considerado promotor do crescimento das plantas, possui em sua composição fitohormônios que atuam como mediadores de processos fisiológicos, promovendo o crescimento e o desenvolvimento das plantas, aumentando o potencial de absorção de água e nutrientes pelas mesmas (DÁRIO et al., 2004; GARCIA et al., 2009).

Dentre os fitohormônios, as auxinas possuem ação característica no crescimento celular, agindo diretamente no aumento da plasticidade da parede da célula, conferindo a esta alongamento irreversível. As citocininas possuem grande capacidade de promover divisão celular, participando assim do processo de alongamento e diferenciação da célula, principalmente quando interagem com as auxinas. $\mathrm{O}$ ácido giberélico $\left(\mathrm{AG}_{3}\right)$ possui efeito marcante no processo de germinação de sementes, ativando enzimas hidrolíticas que atuam no desdobramento das substâncias de reserva da semente. Assim como a auxina e a citocinina, as giberelinas também estimulam o alongamento e divisão celular (VIEIRA; MONTEIRO, 2002; CHIARELO et al., 2007).

$\mathrm{Na}$ literatura, constatam-se diversos resultados positivos para o uso de bioestimulantes nas principais culturas de interesse comercial. Em algodão, foi observado aumento na porcentagem de emergência e vigor de plântulas, além de maior velocidade de crescimento radicular (VIEIRA; SANTOS, 2005; ALBRECHT et al., 2009). Em soja, o uso de bioestimulantes influenciaram a germinação e a biomassa de matéria seca de sementes e resultaram em plantas com maior altura (KLAHOLD et al., 2006; ÁVILA et al.; 2008; CAMPOS et al., 2008). Em arroz, o uso de bioestimulante melhorou as características do sistema radicular em condições de baixa presença de P (GARCIA et al., 2009). Em milho, o uso de bioestimulantes resultou em efeitos positivos para a maioria das características fisiológicas da planta e aumentou a massa seca das raízes das mesmas (SANTOS et al., 2013).

No entanto, o uso de bioestimulantes nem sempre resulta em efeitos positivos. Em milho e soja, o uso de bioestimulante não aumentou a produção de matéria seca, altura de plantas, eficiência fotoquímica,

Nucleus,v.12,n.1,abr.2015 
teor de proteínas e nutrientes (VASCONCELOS, 2006). Da mesma forma, em feijão, o uso desse produto não alterou a altura de plantas e da inserção da primeira vagem, o número de grãos por vagem e a massa de cem grãos (ABRANTES et al., 2011). Essa disparidade de resultados reforça a necessidade de mais estudos relacionados ao uso desses produtos na agricultura.

Considerando todo o potencial efeito do uso de bioestimulantes sobre culturas, o objetivo desse trabalho foi avaliar o efeito de doses de bioestimulante nas características fisiológicas de sementes de arroz.

\section{MATERIAL E MÉTODO}

O experimento foi desenvolvido, parte no Laboratório de Tecnologia de Sementes e parte em casa de vegetação do Campus de Chapadão do Sul, da Universidade Federal de Mato Grosso do Sul (UFMS).

O delineamento experimental foi inteiramente casualizado, utilizando a cultivar de arroz BRS Primavera submetido a doses crescentes de Stimulate $^{\circledR}(0,250,500,750$ e $1000 \mathrm{~mL}$ para $100 \mathrm{~kg}$ de sementes), totalizando cinco tratamentos com quatro repetições.

O Stimulate ${ }^{\circledR}$ possui em sua composição $0,009 \%$ de cinetina (citocinina), 0,005\% de ácido giberélico (giberelina), 0,005\% de ácido indolbutírico (auxina) (STOLLER DO BRASIL, 1998). O produto foi aplicado, com o auxílio de uma pipeta volumétrica, diretamente sobre as sementes dentro de sacos plásticos. O conteúdo foi agitado até a completa homogeneização do produto sobre as sementes.

Para a avaliação da germinação e vigor, as sementes tratadas foram submetidas aos seguintes testes laboratoriais: primeira contagem de germinação (PCG), germinação (G), emergência (E), índice de velocidade de emergência (IVE), comprimento do sistema radicular (CSR), comprimento de parte aérea (CPA), massa de matéria seca da raiz (MSR) e massa de matéria seca da parte aérea (MPA).

Para a realização do teste de germinação, foram utilizadas 200 sementes para cada tratamento, sendo quatro repetições de 50 sementes, que foram acondicionadas em rolos de papel germitest, previamente umedecido com água destilada (BRASIL, 2009). Os rolos foram mantidos em germinador regulado a $25^{\circ} \mathrm{C}$. A primeira contagem da germinação foi realizada no $5^{\circ}$ dia após a montagem do teste, já a segunda contagem foi feita no $14^{\circ}$. Os resultados foram expressos em porcentagem, considerando-se nas contagens a média de plântulas normais de cada tratamento.

No teste de crescimento foram usadas quatro repetições de 20 sementes por tratamento (doses de Stimulate ${ }^{\circledR}$ ). As sementes foram acondicionadas em rolos de papel germitest, previamente umedecidos com água destilada. Os rolos foram agrupados, fechados com saco plástico e colocados em germinador a $25{ }^{\circ} \mathrm{C}$. O comprimento da raiz e a parte aérea das plântulas normais foram medidos aos sete dias após a instalação do teste (NAKAGAWA, 1999).

Após a mensuração do crescimento das plântulas de arroz, esse material foi utilizado para avaliação da massa de matéria seca. Para esta determinação, as amostras foram secas em estufa a $80^{\circ} \mathrm{C}$ durante 24 horas, até atingir massa constante. A massa obtida em cada repetição, dividido pelo número de plântulas normais, resultou na massa média por plântula.

Para a realização do teste de emergência foram utilizadas 100 sementes por tratamento (quatro repetições de 25 sementes). O experimento foi mantido em casa de vegetação, com irrigação controlada. As avaliações foram diárias, até o décimo quarto dia após a semeadura. Os resultados obtidos foram expressos em porcentagem de plântulas normais emergidas. O Índice de Velocidade de Emergência (IVE) foi realizado em conjunto com o teste de emergência. O cálculo do índice de velocidade de emergência ocorreu pelo somatório do número de plantas normais germinadas $(\mathrm{G} 1, \mathrm{G} 2, \mathrm{G} 3, \ldots, \mathrm{Gn})$ a cada dia, 
dividido pelo número de dias decorridos $(\mathrm{N} 1, \mathrm{~N} 2, \mathrm{~N} 3, \ldots, \mathrm{Nn})$ entre a semeadura e a germinação de acordo com a fórmula descrita por Maguire (1962). IVE = G1.N1-1 + G2.N2-1+ G3.N3-1+ ... Gn.Nn-1.

Os dados foram submetidos a análise de variância (ANOVA) e a análise de regressão foi utilizada para verificar o ajuste de modelos polinomiais para variáveis dependentes, em função das doses de Stimulate aplicadas nas sementes, em nível de 5\% de probabilidade. A análise foi feita utilizando o software Sisvar (FERREIRA, 2008).

\section{RESULTADO E DISCUSSÃO}

De acordo com a análise de variância (Tabela 1) observa-se que apenas o comprimento de parte aérea foi influenciado pelas diferentes doses de Stimulate ${ }^{\circledR}$.

As doses utilizadas no tratamento de sementes de arroz não influenciaram significativamente a percentagem de germinação. Estes dados corroboram com os obtidos por Moterle et al. (2011) que ao tratar sementes de soja não verificou a ação das doses de Stimulate ${ }^{\circledR}$ sobre a germinação destas. A quantidade de fitorreguladores absorvida depende fundamentalmente da superfície de contato da semente com o bioregulador (BUCHANAN et al. 2000). Desta forma, a menor absorção do biorregulador pode ter comprometido a eficiência na variável germinação, da cultura estudada.

Vieira (2001) e Vieira et al. (2005), também não encontraram efeito significativo do bioestimulante na qualidade fisiológica de sementes de soja e algodão, respectivamente.

O fato do produto fonte de fitormônios não afetar a percentagem de germinação de algumas culturas, se remete ao acúmulo destes no tecido (MOTERLE et al. 2011), sendo que a germinação é o primeiro processo fisiológico que terá contato com o produto exposto ao organismo vegetal. Os processos de desenvolvimento seguintes terão mais influência da ação do produto sobre os tecidos em formação.

Tabela 1. Valores de F obtidos pela análise de variância da Primeira Contagem de Germinação (PCG), Segunda Contagem de Germinação (G), Comprimento de Parte Aérea (CPA), Comprimento do Sistema Radicular (CSR), Massa de Matéria Seca da Parte Aérea (MSPA), Massa de Matéria Seca de Sistema Radicular (MSSR), Índice de Velocidade de Emergência (IVE), Porcentagem de emergência (E) da cultura do arroz, em função das doses de Stimulate ${ }^{\circledR}$.

\begin{tabular}{ccc}
\hline Variáveis & QM & $\mathrm{CV}(\%)$ \\
\hline PCG $(\%)$ & $98,80000^{\mathrm{ns}}$ & 12,59 \\
G $(\%)$ & $321,2000^{\mathrm{ns}}$ & 12,48 \\
CPA (cm) & $5,408180^{*}$ & 11,65 \\
CSR (cm) & $4,968200^{\text {ns }}$ & 7,03 \\
MSPA (g) & $1,030000^{\text {ns }}$ & 31,82 \\
MSSR (g) & $7,430000^{\text {ns }}$ & 31,30 \\
IVE & $0,409013^{\text {ns }}$ & 58,09 \\
E $(\%)$ & $236,8000^{\text {ns }}$ & 16,88
\end{tabular}

${ }^{\text {ns }}$ As doses dos tratamentos não resultaram em resposta que se enquadra em regressão linear e quadrática. *As doses são significativas para regressão linear e quadrática. CV (\%) - Coeficiente de variância.

Para a avaliação de comprimento de parte aérea verificou-se diferença estatística entre as doses de Stimulate ${ }^{\circledR}$, tendo o tratamento na dose de $1000 \mathrm{ml} 100 \mathrm{Kg}^{-1}$ de sementes proporcionado maior incremento 
em comprimento de parte aérea $(5,07 \mathrm{~cm})$, de forma que a regressão polinomial se enquadrasse em uma equação de primeiro grau, cujo aumento das doses influenciou positivamente no crescimento da parte aérea das plântulas de arroz (Figura 1).

Figura 1. Comprimento da parte aérea das plântulas de arroz $(\mathrm{cm})$ em função das diferentes doses Stimulate ${ }^{\circledR}$.

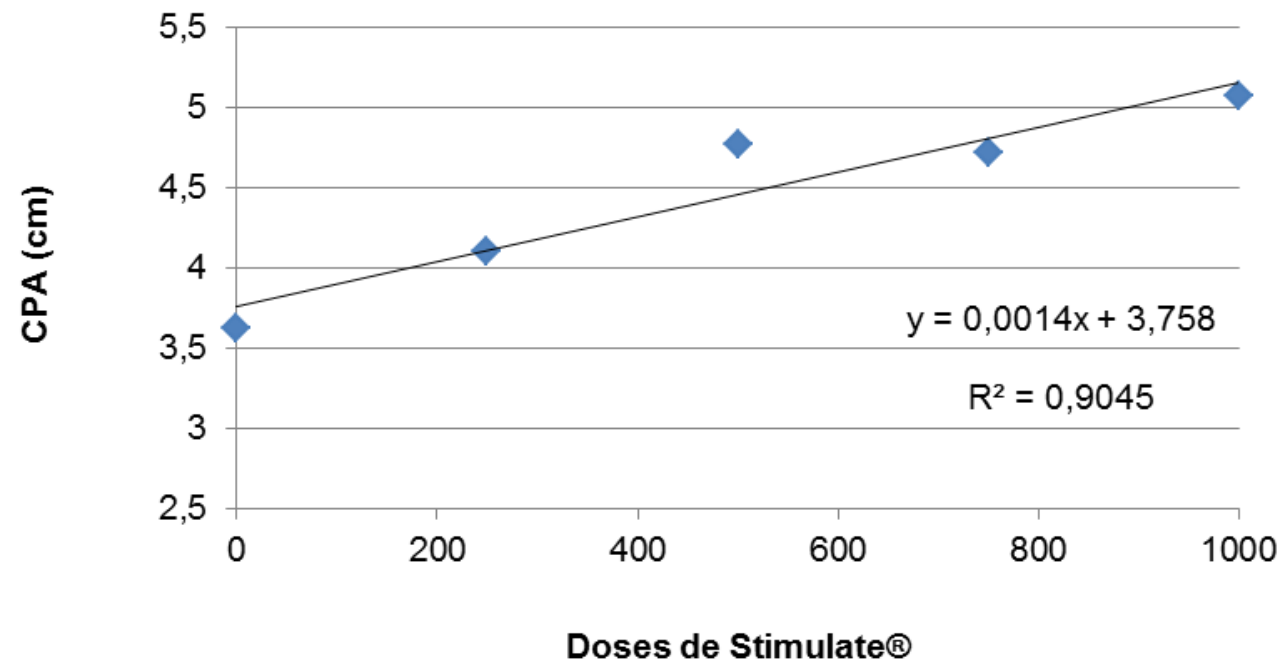

Dados semelhantes foram observados por Viera e Santos (2005), em estudos de doses de Stimulate ${ }^{\circledR}$ no crescimento inicial do algodoeiro, onde verificaram aumento de $29,7 \%$ no comprimento total de plântulas em relação ao tratamento controle. Leonel e Pedroso (2005) também relataram aumentos significativos na altura das plântulas e número de folhas em plântulas de Passiflora alata tratadas com ácido giberélico.

No entanto, vários trabalhos têm mostrado que o uso de biorregulador não interfere no crescimento da parte aérea. Segundo Santos et al. (2013), os tempos de pré-embebição em bioregulador não influenciaram no comprimento da parte aérea de plântulas de girassol em diferentes concentrações do produto. O mesmo foi encontrado por Albuquerque et al. (2004), que ao usar Stimulate ${ }^{\circledR}$ no tratamento de sementes de mamona não encontraram diferença na altura de plantas, porém, proporcionaram plantas com área foliar superiores. Dário et al. (2004) também não verificaram efeito desse produto aplicado via sementes para altura, número de colmos de arroz. Da mesma forma, Reghin et al. (2000) também não observaram significância no uso de doses do produto "Stimulate Mo" em mudas de mandioquinha-salsa no comprimento de parte aérea.

Para o comprimento do sistema radicular, apesar de não sofrer influência significativa do uso de Stimulate ${ }^{\circledR}$ no tratamento de sementes (Tabela 1), tem sido relatados na literatura diversos casos contrários. Reghin et al. (2000), trabalharam com pré-enraizamento de mandioquinha-salsa e encontraram bons resultados do uso de Stimulate Mo como estimulador do sistema radicular. Vieira (2005) alcançou um aumento de 45,5\% no comprimento das raízes das plântulas de algodão. Vieira (2001) observou que a dose de $2,3 \mathrm{~mL}$ de Stimulate ${ }^{\circledR}$ promoveu maior comprimento no sistema radicular das plantas de arroz, o mesmo ocorreu para as plântulas de feijão.

As respostas ao bioestimulante dependem da espécie vegetal e do cultivar utilizado, enquanto algumas espécies enraízam muito melhor com a sua aplicação, outras respondem muito pouco ou até negativamente, isto ocorre porque o balanço hormonal (concentrações e fontes hormonais) das plantas é algo particular de cada material. Vieira (2005) afirma ainda que existe relativamente pouca evidência de 
que tais substâncias reguladoras, presentes no produto Stimulate ${ }^{\circledR}$, funcionem como chave regulatória na emergência da raiz primária.

$\mathrm{Na}$ avaliação de matéria seca da parte aérea também não foi observado diferenças estatísticas entre tratamentos (Tabela 1), o mesmo foi observado por Santos et al. (2013) onde verificaram que o uso do biorregulador composto por auxina, citocinina e giberelina, não influenciou na avaliação de massa seca da parte aérea. Dados semelhantes foram verificados por Verona et al. (2010), que trabalharam com milho submetido a tratamento com Stimulate ${ }^{\circledR}$ via semente e inoculação de Azospirillum sp. e não verificaram respostas significativas entre tratamentos.

A massa de matéria seca do sistema radicular não sofreu a influência da aplicação das diferentes doses de Stimulate ${ }^{\circledR}$ (Tabela 1), corroborando com Verona et al. (2010) que trabalharam com milho e não verificaram diferença significativa na comparação de médias para massa seca de raiz. Dados semelhantes foram obtidos por Mortele et al. (2011), que concluíram que a produção de biomassa da matéria seca de plântulas de soja não foi influenciada pela aplicação crescente de bioestimulante.

Já Garcia et al. (2009) afirmam que o uso de bioestimulantes para a cultura do arroz, resulta em maior crescimento de raízes, somente nas condições de baixo fornecimento de fósforo, ou seja, o bioestimulante interfere consideravelmente no desenvolvimento das raízes quando há menor fertilidade no solo. Quando a fertilidade é considerada alta, o uso do produto não influência o desenvolvimento das raízes.

A percentagem de emergência também não apresentou diferença estatística significativa para doses de Stimulate ${ }^{\circledR}$ (Tabela 1). Segundo Vieira e Santos (2005) a emergência de plântulas de algodão em terra vegetal aos quatro dias após a semeadura, com sementes submetidas a sete doses de bioestimulante, resultou em acréscimo de 2,2\% na avaliação. Dados semelhantes foram obtidos por Santos et al. (2013) que verificaram maior porcentagem de emergência de plântulas de girassol em substrato quando utilizaram Stimulate ${ }^{\circledR}$ na germinação de sementes.

O IVE (Índice de velocidade de emergência) também não apresentou diferenças estatísticas entre os tratamentos (Tabela 1). Dados semelhantes foram obtidos por Santos et al. (2013), que não encontraram resultado significativo para a interação (Genótipos X Doses de Stimulate $^{\circledR}$ ) quando avaliaram a característica IVE. Resultados contrastantes foram alcançados por Chiarelo et al. (2007) que comprovaram uma correlação positiva dos tratamentos com aplicação de biorreguladores na semente, nos quais houve maior IVE, correspondendo ao tratamento com a utilização da maior dose do Stimulate.

\section{CONCLUSÃO}

- O comprimento de parte aérea sofreu a influência positiva das doses crescentes de Stimulate

- A germinação, o comprimento de raiz, a massa de matéria seca da raiz e parte aérea, o índice de velocidade de emergência e a percentagem de emergência não foram afetados pelas doses de Stimulate.

- Doses de $1000 \mathrm{~mL}$ para $100 \mathrm{~kg}$ sementes, podem ser utilizadas no arroz, aumentando o comprimento da parte aérea, mas sem afetar a germinação das sementes.

\section{REFERÊNCIAS}

ABRANTES, F. L. et al. Uso de regulador de crescimento em cultivares de feijão de inverno. Pesquisa Agropecuária Tropical, v. 41, n. 2, p. 148-154, 2011. 
ALBRECHT, et al. Aplicação de biorregulador na produtividade do algodoeiro e qualidade de fibra. Scientia Agraria, v. 10, p. 191-198, 2009.

ALBUQUERQUE, R.C. et al. Efeitos do bioestimulante Stimulate ${ }^{\circledR}$ em sementes pré-embebidas de mamona (Ricinus communis L.). In: CONGRESSO BRASILEIRO DE MAMONA: ENERGIA E SUSTENTABILIDADE, 1,2004, Campina Grande. Anais... Campina Grande, Embrapa Algodão. p.47-48.

ÁVILA, M. R. et al. Bioregulator application, agronomic efficiency, and quality of soybean seeds. Scientia Agricola, v. 65, p. 567- 691, 2008.

BRASIL. Ministério da Agricultura, Pecuária e Abastecimento. Regras para análise de sementes. Brasília: MAPA/ACS, 2009. 365p.

BUCHANAN, B. B.; GRUISSEM, W.; JONES, R.L. Biochemistry \& Molecular Biology of Plants. Rockville, American Society of Plant Physiologists. 2000, 1367 p.

CAMPOS, M. F. et al. Análise de crescimento em plantas de soja tratadas com substâncias reguladoras. Revista Biotemas, v. 21, p. 53-63, 2008.

CASTRO, G. S. A. et al. Tratamento de sementes de soja com inseticidas e um bioestimulante. Pesquisa Agropecuária Brasileira, v. 43: p.1311-1318, 2008.

CHIARELO, C. et al. Efeitos do uso de Stimulate ${ }^{\circledR}$ no desempenho da cultura do arroz irrigado. In.: CONGRESSO DE INICIAÇÃO CIENTIFICA, 16, 2007, Pelotas. Anais...Pelotas, UFPEL.

CONAB. Companhia Nacional de Abastecimento. 2014. Acompanhamento da safra brasileira de grãos, Safra 2013/2014. Disponível em:

$<$ http://www.conab.gov.br/OlalaCMS/uploads/arquivos/14_10_09_14_54_26_boletim_graos_outubro_20 14.pdf > . Acessado em: 26 de setembro de 2014.

DÁRIO, G. J. A. et al. Influência do Uso de Fitorregulador no Crescimento do Arroz Irrigado. Revista da FZVA, v. 11, n. 1, p. 86-94, 2004.

EMBRAPA . Empresa Brasileira de Pesquisa Agropecuária. Cultivo de arroz irrigado. 2005. Disponível em: 〈http://sistemasdeproducao.cnptia.embrapabr/FontesHTML/Arroz/ArrozIrrigadoBrasil/cap10.htm >. Acessado em: 12 de setembro de 2014.

FERREIRA, D. F. SISVAR: um programa para análises e ensino de estatística. Revista Symposium, Lavras, v. 6, n. 1, p. 36-41, 2008.

GARCIA, R. A. et al. Crescimento aéreo e radicular de arroz de terras altas em função da adubação fosfatada e bioestimulante. Bioscience Journal, v. 25, n. 4, p. 65-72, 2009.

GIACOMELI, R. et al. Qualidade fisiológica de sementes de arroz irrigado por aspersão e inundação. In.: CONGRESSO BRASILEIRO DE ARROZ IRRIGADO, 6, 2013, Santa Maria. Anais... Santa Maria, 2013.

KLAHOLD, C. A. et al. Resposta da soja (Glycine max (L.) Merrill) à ação de bioestimulante. Acta Scientiarum Agronomy, v. 28, n. 2, p. 179-185, 2006.

LEONEL, S.; PEDROSO, C. J. Produção de mudas de maracujazeiro-doce com o uso de biorregulador. Revista Brasileira de Fruticultura, v.27, n.1, p.107-109, 2005.

MAGUIRE, J. D. Speeds of germination-aid selection and evaluation for seedling emergence and vigor. Crop Science, v. 2, p. 176-177, 1962. 
MOTERLE, L. M. et al. Efeito de biorregulador na germinação e no vigor de sementes de soja. Revista Ceres, v. 58, n. 5, p. 651-660, 2011.

NAKAGAWA, J. Testes de vigor baseados na avaliação das plântulas. In: VIEIRA, R. D.; CARVALHO (eds.). Testes de vigor em sementes. Jaboticabal: FUNEP. p. 48-85. 1999.

REGHIN, M. Y.; OTTO, R. F. E.; SILVA, J. B. C. "Stimulate Mo" e proteção com tecido "não tecido" no pré-enraizamento de mudas de mandioquinha-salsa. Horticultura Brasileira, v. 18, n.1, p. 53-56, 2000.

SANTOS, C. A. C. et al. Stimulate na germinação de sementes, emergência e vigor de plântulas de girassol. Bioscience Journal, v. 29, n. 2, p. 605-616, 2013.

SANTOS, M. S. et al. Uso de bioestimulantes no crescimento de plantas de Zea mays L. Revista Brasileira de Milho e Sorgo, v. 12, n. 3, p. 307-318, 2013.

SILVA, T. T. A. et al. Qualidade fisiológica de sementes de milho na presença de bioestimulantes. Ciência Agrotecnologia, v. 32, n. 3, p. 840-846, 2008.

STOLLER DO BRASIL. Stimulate ${ }^{\circledR}$ Mo em hortaliças: Cosmópolis: Divisão Arbore, 1998. 1v. (Informativo técnico).

USDA. United States Department of Agriculture. Production, supply and distribution online: custom query. 2009. Disponível em: $<$ http://www.fas.usda.gov/psdonline/psdQuery.aspx $>$. Acessado em: 15 de setembro de 2014.

VASCONCELOS, A. C. F. de. Uso de bioestimulantes nas culturas de milho e de soja. Piracicaba: ESALQ/USP, 2006.

VERONA, D. A. et al. Tratamento de sementes de milho com Zeavit, Stimulate e inoculação com Azospirillum sp. In.: CONGRESSO NACIONAL DE MILHO E SORGO, 28, 2010, Goiânia. Anais... Goiânia, 2010. CD-ROM.

VIEIRA, E. L. Stimulate $10 \mathrm{X}$ na germinação de sementes, vigor de plântulas e crescimento inicial de plantas de algodoeiro. In: V Congresso Brasileiro de Algodão, Salvador. Anais... Embrapa Algodão. 2005. p.163-163.

VIEIRA, E. L. Ação de bioestimulantes na germinação de sementes, vigor de plântulas, crescimento radicular e produtividade de soja (Glycine max (L.) Merrill), feijoeiro (Phaseolus vulgaris L.) e arroz (Oryza sativa L.). Piracicaba, 2001. 122 f. Tese (Doutorado em Fitotecnia) - Escola Superior de Agricultura Luis de Queiroz, Universidade de São Paulo.

VIEIRA, E. L. et al. Stimulate no sistema de produção da soja. In: REUNIÃO DE PESQUISA DE SOJA NA REGIÃO CENTRAL DO BRASIL, 27., 2005, Cornélio Procópio. Resumos... Cornélio Procópio, 2005. p.82-83.

VIEIRA, E. L.; MONTEIRO, C. A. Hormônios vegetais. In: CASTRO, P. R. C., SENA, J. O. A., KLUGE, R. A. (Eds.). Introdução à fisiologia do desenvolvimento vegetal. Maringá, Eduem. 2002. p.79-104.

VIEIRA, E. L.; SANTOS, C. M. G. Efeito de bioestimulante no crescimento e desenvolvimento inicial de plantas de algodoeiro. Magistra, v. 17, p. 1-8, 2005. 